Editorial

\title{
Ischemic maculopathy: anoccult cause of an irreversible visual loss
}

Keywords: ischemic maculopathy, macular ischemia, causes, irreversible visual loss

\section{Editorial}

In this editorial, I aimed to summarize the ischemic maculopathy (IM) or macular ischemia as a cause of irreversible visual loss because, to date, there is no successful treatment method for this fundus angiographic entity. Ischaemic maculopathy is a vision-threatening disorder because it does not respond to treatment and it causes severe irreversible visual loss. In IM, ischemia can occur in both the retina excluding macula and the macula. The microvascular changes including the breakdown of capillary walls and/or enlargement or blockage of capillaries located near the fovea and the loss of capillaries in the macula are responsible for maculopathy. IM can occur with or without macular edema. It causes painless and gradually severe visual loss in color and sharp vision. ${ }^{1-8}$

Ischemic maculopathy is characterized by as enlarged or irregular FAZ (foveal avascular zone), the loss of perfusion to the capillary network surrounding the FAZ, the presence of FAZ abnormalities, capillary nonperfusion areas in the macula and the presence of microaneurysms at the border of FAZ due to perifoveal capillary occlusion in fundus angiography. IM is not caused by increased by vascular leakage; it is induced by microvascular blockage and enlargement, with capillary loss and adjacent edema. ${ }^{1-8}$ The detection of IM is extremely difficult without the use of fundus angiography. If the visual loss is not explained ophthalmoscopically or optical coherence tomographically, especially in a diabetic patient, IM is usually responsible for unexplained visual loss, even if the clinical stage of the disease is early or mild. ${ }^{1-8}$ Ischaemic maculopathy can occur in non-proliferative or proliferative diabetic retinopathy (DR),
Volume 7 Issue I - 2017

\section{Burak Turgut}

Department of Ophthalmology, Firat University, Turkey

Correspondence: Burak Turgut, Associate Professor of Ophthalmology, Firat University, Faculty of Medicine, Department of Ophthalmology, 231 19, Elazig, Turkey, Tel +904242333555, Email burakturgut@firat.edu.tr

Received: May 17, 2017| Published: May 18, 2017

retinal arterial or venous occlusion, retinal arteritis, retinopathy of prematurity (ROP), ocular ischemic syndrome, talc retinopathy, proliferative or non-proliferative diabetic retinopathy, pars planitis, Sarcoidosis, cytomegalovirus retinitis caused by AIDS, familial exudative vitreoretinopathy, Eales' disease involving the macula. ${ }^{5-20}$ Additionally, it has been reported that it can be developed following intravitreal antivascular endothelial growth factor injection. ${ }^{21,22}$ However, it can also develop in the idiopathic form. ${ }^{23}$ The common causes of IM have been given in Table 1. The area of FAZ obtained optical coherence tomography angiography and fluorescein angiography ranges between $0.3-0.5 \mathrm{~mm}$ in healthy subjects. The measurement of FAZ area and the evaluation of FAZ integrity are very important because the enlargement of FAZ precedes the occurrence of microaneurisms and the diabetic retinopathy in this stage can be reversed. ${ }^{24,25}$ Ischemic maculopathy is an ophthalmoscopically occult maculopathy if there is no associated with cotton wool spots. Thus, the evaluation of FAZ in the cases with clinically and ophthalmoscopically unexplained visual loss is critical for both early treatment and prophylaxis.

Table I The common causes of ischemic maculopathy or macular ischemia ${ }^{5-23}$

The causes of ischemic maculopathy or macular ischemia

Nonproliferative or proliferative diabetic retinopathy

Retinal arterial or venous occlusion/obstruction

Embolic maculopathy (Talc retinopathy)

Ocular ischemic syndrome

Sarcoidosis

Pars planitis

Retinopathy of prematurity

Familial exudative vitreoretinopathy

Eales' disease involving the macula

Cytomegalovirus Retinitis in Patients with AIDS

Intravitreal antivascular endothelial growth factor injection

Retinal vasculitis (especially arteritis)

Idiopathic 


\section{Acknowledgements}

None.

\section{Conflicts of interest}

The authors declare there are no conflicts of interest.

\section{References}

1. Wu LZ, Huang ZS, Wu DZ, et al. Characteristics of the capillary-free zone in the normal human macula. Jpn J Ophthalmol. 1985;29(4):406411 .

2. Olk RJ, Lee CM. Indications for fluorescein angiography in the management of diabetic retinopathy. In: Papadopoulos D, editor. Diabetic Retinopathy, Practical Management. Philadelphia: JB, USA. Lippincott Company; 1993:129-139.

3. Bresnick GH, Condit R, Syrjala S, et al. Abnormalities of the foveal avascular zone in diabetic retinopathy. Arch Ophthalmol. 1984;102:1286-1293.

4. Bandello F, Pognuz R, Polito A, et al. Diabetic macular edema: classification, medical and laser therapy. Semin Ophthalmol. 2003;8(4):251-258.

5. Bresnick GH, Engerman R, Davis MD, et al. Patterns of ischemia in diabetic retinopathy. Trans Sect Ophthalmol Am Acad Ophthalmol Otolaryngol. 1976;81(4 Pt 1):OP694-709.

6. Mansour AM, Schachat A, Bodiford G, et al. Foveal avascular zone in diabetes mellitus. Retina. 1993;3(2):125-128.

7. Arend O, Wolf S, Jung F, et al. Retinal microcirculation in patients with diabetes mellitus: Dynamic and morphological analysis of perifoveal capillary network. Br J Ophthalmol. 1991;75(9):514-518.

8. Bresnick GH, Condit R, Syrjala S, et al. Abnormalities of the foveal avascular zone in diabetic retinopathy. Arch Ophthalmol. 1994;102(9):1286-1293.

9. Akova YA, Jabbur NS, Foster CS. Ocular presentation of polyarteritis nodosa. Clinical course and management with steroid and cytotoxic therapy. Ophthalmology. 1993;100(12):1775-1781.

10. Bullen CL, Liesegang TJ, McDonald TJ, et al. Ocular complications of Wegener's granulomatosis. Ophthalmology. 1983;90(3):279-290.

11. Jabs DA, Fine SL, Hochberg MC, et al. Severe retinal vasoocclusive disease in systemic lupus erythematous. Arch Ophthalmol. 1986;104(4):558-563.
12. Elliot AJ. 30-year observation of patients with Eale's disease. Am J Ophthalmol. 1975;80(3 Pt 1):404-408.

13. Watanabe Y, Takeda N, Adachi-Usami E. A case of frosted branch angiitis. Br J Ophthalmol. 1987;71:553-558.

14. Ho AC. Hemoglobinopathies. In: Yanoff M, Duker JS, editors. Ophthalmology. 3rd edn. Philadelphia: Mosby, USA. Elsevier; 2009:626-630.

15. Chang TS, Aylward GW, Davis JL, et al. Idiopathic retinal vasculitis, aneurysms, and neuro-retinitis. Retinal Vasculitis Study. Ophthalmology. 1995;102(7):1089-1097.

16. Susac JO, Egan RA, Rennebohm RM, et al. Susac's syndrome:1975-2005 microangiopathy/autoimmune endotheliopathy. $J$ Neurol Sci. 2007;257(1-2):270-272.

17. Akduman L, Feiner MA, Olk RJ, et al. Macular ischemia as a cause of decreased vision in a patient with acquired immunodeficiency syndrome. Am J Ophthalmol. 1997;24(5):699-702.

18. Romano MR, Valldeperas X, Romano F. Bilateral ischemic maculopathy in a patient with AIDS. Eur J Ophthalmol. 2006;16(5):761-763.

19. Cunningham ET, Levinson RD, Jampol LM, et al. Ischemic maculopathy in patients with acquired immunodeficiency syndrome. Am JOphthalmol. 2001;132(5):727-733.

20. Arevalo JF, Garcia RA, Arevalo FA, et al. Unilateral Ischemic Maculopathy Associated with Cytomegalovirus Retinitis in Patients with AIDS: Optical Coherence Tomography Findings. J Ophthalmic Vis Res. 2015;10(4):487-490.

21. Goel N, Kumar V, Ghosh B. Ischemic maculopathy following intravitreal bevacizumab for refractory diabetic macular edema. Int Ophthalmol. 2011;31(1):39-42.

22. Lee SJ, Koh HJ. Enlargement of the foveal avascular zone in diabetic retinopathy after adjunctive intravitreal bevacizumab (avastin) with pars plana vitrectomy. J Ocul Pharmacol Ther. 2009;25(2):173-174.

23. Kasar K, Turgut B, Demir T, et al. Idiopathic Macular Ischemia: A Case Report. Int J Ophthalmic Pathol. 2012;1:2.

24. John D, Kuriakose T, Devasahayam S, et al. Dimensions of the foveal avascular zone using the Heidelberg retinal angiogram-2 in normal eyes. Indian J Ophthalmol. 2011;59(1):9-11.

25. Samara WA, Say EA, Khoo CT, et al. Correlation of foveal avascular zone size with foveal morphology in normal eyes using optical coherence tomography angiography. Retina. 2015;35(11):2188-2195. 